Abstracta Iranica Abstracta Iranica

Revue bibliographique pour le domaine irano-aryen

Volume 32-33 | 2013

Comptes rendus des publications de 2009-2010

\title{
Maria Macuch. The Hērbedestān as a Legal Source: A Section of the Inheritance of a Convert to Zoroastrianism
}

\section{Mihaela Timus}

\section{CpenEdition} Journals

Édition électronique

URL : http://journals.openedition.org/abstractairanica/40803

DOI : 10.4000/abstractairanica.40803

ISSN : 1961-960X

Éditeur :

CNRS (UMR 7528 Mondes iraniens et indiens), Éditions de l'IFRI

\section{Édition imprimée}

Date de publication : 1 décembre 2013

ISSN : 0240-8910

Référence électronique

Mihaela Timus, « Maria Macuch. The Hērbedestān as a Legal Source: A Section of the Inheritance of a Convert to Zoroastrianism », Abstracta Iranica [En ligne], Volume 32-33 | 2013, document 309, mis en ligne le 01 juillet 2016, consulté le 26 septembre 2020. URL : http://journals.openedition.org/ abstractairanica/40803 ; DOI : https://doi.org/10.4000/abstractairanica.40803

Ce document a été généré automatiquement le 26 septembre 2020.

Tous droits réservés 


\title{
Maria Macuch. The Hērbedestān as a Legal Source: A Section of the Inheritance of a Convert to Zoroastrianism
}

\author{
Mihaela Timus
}

\section{RÉFÉRENCE}

Maria Macuch. « The Hērbedestān as a Legal Source: A Section of the Inheritance of a Convert to Zoroastrianism », in : C. A. Bromberg, N. Sims-Williams, U. Sims-Williams, eds., BAI: Iranian and Zoroastrian Studies in Honor of Prods Oktor Skjervø, vol. 19, 2005 [2009], Detroit (Michigan), Iowa State University Press, 2009, p. 91-102.

1 En présentant le Hērbedestān (H.) comme le seul texte avestique (accompagné du zand) conservé qui prend en compte, d'une manière détaillée, des questions liées à l'éducation religieuse des Zoroastriens, l'A. fournit une nouvelle transcription et traduction du zand du chapitre 12 (H 12.1-7), accompagnées d'un très dense commentaire. Malgré les éditions antérieures du Hērbedestān (H), Humbach - Elfenbein (1990) et Kotwal - Kreyenbroek (1992), l'A. considère que bon nombre de notions juridiques et théologiques restent encore mal comprises. Questions envisagées: 1 . Le cas de figure pris en discussion concerne le plus probablement la conversion d'un chrétien au zoroastrisme. Ses enfants (naturels) n'ayant pas atteint l'âge adulte (aburnāyīg) sont convertis également. Digression sur les trois catégories d'enfants selon le droit sassanide (a. conformes à la loi ; b. progénitures naturelles; c. adoptés) qui montre que le droit des communautés chrétiennes en tirait ses racines. Preuve en est le Corpus Iuris de Jesuboxt, conservé uniquement en version syriaque, qui connaît la même division. 2. Obligations du converti de protéger l'épouse qui reste dans la religion ancienne, bien que le mariage ne puisse plus être consommé. Le vocabulaire technique ne comporte pas le «divorce» (az zanih hištan), mais une autre expression voisine : az 
zanih nē appār, « (la femme) n'est pas perdue ou privée de ses droits d'épouse ». L'A. souligne que le droit sassanide laisse ouverte la possibilité de la polygamie : le converti peut garder la femme chrétienne et, en même temps, en épouser une autre, zoroastrienne. 3. Les droits de la femme du converti : interdiction de la frapper, de la perturber ou de lui causer du tort (orig. m. p. wizūdan, verbe mal compris par les éditeurs précédents, signale l'A.) par quelque moyen que ce soit. 4. Pour ce qui est des revenus dont la femme non convertie peut bénéficier, son indemnité quotidienne doit rester dans la propriété de la communauté zoroastrienne. 5-7. Questions liées au droit d'héritage de la propriété du converti.

\section{AUTEURS}

\section{MIHAELA TIMUS}

Institut d'Histoire des Religions, Bucarest 